\title{
Risk factors for asthma exacerbation among Hajj pilgrims: a case study from DKI Jakarta, Indonesia
}

Anshari Saifuddin, Ujainah Zaini Nasir, Iris Rengganis, Hamzah Shatri

Check for updates

pISSN: 0853-1773 • elSSN: 2252-8083 https://doi.org/10.13181/mji.oa.204170 Med J Indones. 2020;29:190-7

Received: August 30, 2019 Accepted: May 21, 2020

\section{Authors' affiliations:}

Department of Internal Medicine, Faculty of Medicine, Universitas Indonesia,

Jakarta, Indonesia

\section{Corresponding author:}

Anshari Saifuddin

Department of Internal Medicine, Faculty of Medicine, Universitas Indonesia, Jalan Pangeran Diponegoro No. 71, Kenari, Senen, Central Jakarta 10430,

DKI Jakarta, Indonesia

Tel/Fax: +62-21-1500135

E-mail: sorihsb@gmail.com

\begin{abstract}
BACKGROUND Hajj pilgrims are prone to asthma exacerbation because of the high transmission rate of respiratory infections, severe environmental factors, and highintensity activities during the Hajj. Well-controlled asthma status and preventive efforts prior to the Hajj could reduce such exacerbations. This research aimed to determine the risk factors of asthma exacerbation during the Hajj to help establish preventive measures.
\end{abstract}

METHODS Participants were evaluated at community health centers (puskesmas) through history taking, physical examination, and spirometry. The risk factors examined included a history of exacerbation one year before the Hajj, obesity, comorbidities (e.g., diabetes mellitus, hypertension, coronary heart disease), lung function, smoking, fitness level, and influenza vaccination. Asthma exacerbation while in Saudi Arabia was determined through direct observations by authors and physicians assigned to Hajj pilgrim groups and analysis of data obtained from questionnaires distributed to the pilgrims before their departure. Odds ratios (OR) were calculated using logistic regression.

RESULTS Among 68 pilgrims with asthma, exacerbation occurred in 27 (40\%) pilgrims. Risk of asthma exacerbation was significantly increased in the pilgrims with a history of exacerbation one year before the Hajj $(\mathrm{OR}=4.27 ; 95 \%$ confidence interval $[\mathrm{Cl}]=$ $1.156-15.829 ; p=0.029)$ and obesity grade II $(\mathrm{OR}=4.02 ; 95 \% \mathrm{Cl}=1.151-14.097 ; p=0.029)$. Other factors, including smoking, comorbidities, lung function, fitness level, obesity grade I, and influenza vaccination, were not significantly related to exacerbation.

CONCLUSIONS Obesity grade II and history of asthma exacerbation one year before the Hajj are strong factors for asthma exacerbation during Hajj pilgrims.

KEYWORDS asthma, exacerbation, risk factors
Muslims deemed physically and financially capable are obligated to carry out one of the great pillars of Islam, the Hajj. More than 2 million pilgrims from over 140 countries are estimated to undertake the Hajj each year. ${ }^{1}$ In Indonesia, determining whether one is capable of embarking on the Hajj is guided by Regulation No. 15 of the Minister of Health (2016), which describes health services for Hajj pilgrims. The regulation requires good physical health for one to perform Hajj. ${ }^{2}$ Early preparation through government efforts must be carried out to meet health criteria and deliver healthy pilgrims from Indonesia to Saudi Arabia. The Hajj is an activity that requires physical preparation from its pilgrims. The activities undertaken by pilgrims include long-distance walking and stays in dry and barren areas. The difference in climate between Indonesia and Saudi Arabia could also affect pilgrims' physical tolerance. ${ }^{3}$

Respiratory disease is one of the five most common diseases affecting pilgrims during the Hajj 
and one of the five leading causes of death during this event. Asthma, in particular, requires extensive monitoring efforts to prevent disease exacerbation during the Hajj. ${ }^{4}$ Asthma exacerbation is one of the most common medical emergencies during the Hajj. A 2017 Hajj health report revealed that respiratory problems are the second leading cause of death after cardiovascular diseases. Among the emergency response cases compiled by the Fast Response Team (Tim Gerak Cepat), asthma as the chief complaint affected 375 pilgrims..$^{5}$ In the study on pilgrims during the winter season, asthma is one of the most prevalent reasons for pilgrims to have hospital admission. ${ }^{6}$ Asthma and chronic obstructive pulmonary disease (COPD) exacerbation affected $14.4 \%$ of the subjects, only after a pneumonia (39.4\%). Asthma and COPD were the most common comorbidities in severe sepsis cases among Hajj pilgrims and $54.7 \%$ of patients treated in intensive care units had these comorbidities. ${ }^{7}$

Some risk factors for asthma exacerbation are influenza vaccination, history of previous exacerbations, smoking, lung function reduction, low fitness level, and obesity. It is needed to know the risk factors to establish asthma exacerbation prevention in order to support pilgrims in completing their pilgrimages. Therefore, this study was conducted to delineate the risk factors of asthma exacerbation in pilgrimage from Indonesia during the Hajj.

\section{METHODS}

This cohort prospective study was carried out at 30 public health centers (puskesmas) in Jakarta for the first observation, and then at the Pondok Gede Jakarta Hajj Dormitory several days before embarkation for the second observation, and during the pilgrimage in Saudi Arabia for the third observation. This study was conducted from April 2018 to September 2018. Subjects who had undergone health assessments in puskesmas which is mandatory and were diagnosed with bronchial asthma were recruited from the Integrated Hajj Computerization System (Sistem Komputerisasi Haji Terpadu), a system recording all Indonesian pilgrims. First, the researchers evaluated asthma diagnosis of all subjects in the puskesmas to ensure the diagnosis. We used criteria to diagnose asthma from the Global Initiative for Asthma guidelines (2017 edition). The criteria were (1) history of variable respiratory symptoms, such as wheezing, shortness of breath, chest tightness, and cough (generally have more than one of these symptoms) and often triggered by exercise, laughter, allergens, or cold; (2) evidence of variable expiratory air flow limitation (low forced vital capacity [FVC] with forced expiratory volume in one second $\left(\mathrm{FEV}_{1}\right) /$ forced vital capacity (FVC) ratio reduction and variation in increase of $\mathrm{FEV}_{1} \%$ by $>12 \%$ and $200 \mathrm{ml}$ after inhaling bronchodilator. ${ }^{8}$ The asthma control test (ACT) is a survey used to determine the level of asthma control and includes five questions scored from 1 to 5 ; this test probes a patient's level of activity, frequency of shortness of breath and symptoms of asthma, use of exacerbating drugs, and patient's own assessment of asthma control.9,10 The ACT score $\leq 19$ was considered as not controlled, 20 to 24 as partially controlled, and $\geq 25$ as completely controlled. The ACT assesses the symptoms of asthma in the last four weeks. ${ }^{10}$ ACT scores were calculated by the researchers at the puskesmas, before the embarkation, and during the Hajj.

\section{Sample size}

The sample size was determined to compare two independent proportion difference. We used the proportion of asthma patients with comorbidities (e.g., coronary heart disease [CHD]) and asthma exacerbation (10\%). ${ }^{11}$ By applying $Z \alpha=1.96$ and $Z_{\beta}=$ 0.842 , the minimal sample size was 58 subjects.

\section{Data collection}

The data collected in this study included: (1) patient history (e.g., age, gender, occupation, education, history of vaccination, history of asthma exacerbation, smoking habits, and history of asthma triggers/allergies before departure); (2) general physical examination; (3) spirometry to determine the lung function ( $\mathrm{FEV}_{1}$, $\mathrm{FEV}_{1} \%, \mathrm{FEV}_{1} / \mathrm{FVC}$ ); (4) fitness level (maximal oxygen consumption $\left[\mathrm{VO}_{2} \max \right]$ ) evaluated with the Rockport test or six-minute walk test conducted at the puskesmas; and (5) ACT scores. All subjects were provided with an evaluation sheet during the embarkation period at the Pondok Gede Hajj Dormitory and asked them to complete the form if they experienced asthma exacerbations during their Hajj.

\section{Inclusion and exclusion criteria}

Subjects were included in this study if they were 2018 Hajj pilgrims with bronchial asthma and from 
Jakarta Province. Subjects were excluded if they had a contraindication to spirometry examination, had chronic lung diseases other than bronchial asthma (e.g., COPD, lung tuberculosis, or lung cancer) or heart problems limiting physical activity or limited movement due to certain diseases (e.g., history of stroke or severe osteoarthritis), had difficulty in communication (e.g., cognitive decline), or were unwilling to take part in the study. Subjects were asked to complete an informed consent form before their inclusion in this study.

\section{Variables}

Seven variables were analyzed to determine their relationship with asthma exacerbation. The included variables were as follows: (1) history of exacerbation, which was defined as a history of exacerbation one year before the Hajj (yes or no); (2) fitness level, which was defined as aerobic capacity based on $\mathrm{VO}_{2}$ max values determined according to the 1972 American Heart Association Cardiorespiratory Fitness Chart; 12,13 (3) obesity, which was defined as a body mass index (BMI) $\geq 25 \mathrm{~kg} / \mathrm{m}^{2}$; (4) influenza vaccination, which was defined as a history of influenza vaccination one year before departure (yes or no); (5) comorbidities, which was defined as a diagnosis of diabetes mellitus, hypertension, or CHD before departure; (6) smoking habit, which was defined by a history of or active smoking (yes or no); and (7) lung function as measured by spirometry.

Fitness level was categorized using the 1972 American Heart Association Cardiorespiratory Fitness Chart into five levels: very poor, poor, fair, good, and very good. However, for the analysis, we divided these into two categories, i.e.: less (very poor and poor level) and fairly (fair, good, and very good level). Obesity was further graded as follows: obesity grade $I$ (BMI $=25-$ $\left.29.9 \mathrm{~kg} / \mathrm{m}^{2}\right)$ and obesity grade II (BMI $\left.\geq 30 \mathrm{~kg} / \mathrm{m}^{2}\right)$ based on World Health Organization criteria for the AsiaPacific region. The spirometry test was carried out according to American Thoracic Society guidelines. ${ }^{14}$ Spirometry was conducted three times before and three times after the use of a salbutamol inhaler and the best result was used for the analysis. Patients were asked to do this in standing position. $\mathrm{FEV}_{1}, \mathrm{FEV}_{1} \%$, and $\mathrm{FEV}_{1} / \mathrm{FVC}$ were obtained from the spirometry test. Lung function before departure was classified as $\mathrm{FEV}_{1} \% \leq 80 \%$ or $>80 \%$. We applied the 2012 guidelines of the National Heart, Lung and Blood Institute, which classified asthma control according to $\mathrm{FEV}_{1} \%$ (well controlled: $>80 \%$; poorly controlled: $\leq 80 \%) .{ }^{15}$

\section{Determination of asthma exacerbation}

Indonesian Hajj Health Team (Tenaga Kesehatan Haji Indonesia; TKHI) physicians are responsible for addressing health problems in their assigned Hajj group. During embarkation, we coordinated with TKHI physicians to observe the subjects directly and determine acute asthma exacerbation during their pilgrimage in Saudi Arabia. Exacerbation in Saudi Arabia was determined in three ways: (1) direct visits by us to the hotel in which the subjects stayed and follow up through WhatsApp and telephone; (2) daily direct observations by the TKHI physician; and (3) analysis of the research questionnaires provided to the pilgrims before their departure. If a questionnaire result was not in accordance with the results reported to the authors and observed by the TKHI physician, the subject was asked to submit a complete history and physical examination. The authors and TKHI physician then discussed whether the results were valid to minimize discrepancies between the questionnaire results and the direct observations. Subjects were considered to experience an exacerbation if they had symptoms of shortness of breath or dyspnea varying in time and intensity, arising from some trigger, and accompanied by coughing or wheezing.

\section{Statistical analysis}

Data recorded were validated and processed using SPSS version 22 (IBM Corp, USA). In this study, the basic characteristics of the research subjects are presented as tables and categorical data are presented as quantities and percentages. Numerical data are presented in the form of means with standard deviations (SDs) if their distribution is normal and in the form of medians with maximum and minimum values if their distribution is not normal. Relationships between independent and dependent variables were determined by using the chi-squared test. The associations were expressed using prevalence ratio. Multivariate logistic regression analysis was used for variables that had $p<0.25$ determined from bivariate analysis.

\section{RESULTS}

Among 8,519 pilgrims from DKI Jakarta who had registered in the SISKOHAT in 2018, 61 pilgrims had asthma. Two eligible subjects were excluded because coincidence with tuberculosis and lung 
cancer. In addition, the TKHI physicians reported that 11 pilgrims were diagnosed with asthma in Saudi Arabia, but 2 pilgrims refused to be included in this study. Thus, a total of 68 pilgrims with asthma were finally included in this study. Table 1 shows the demographic and clinical characteristics of the subjects.

Most of the subjects with asthma were female (68\%) and aged younger than 60 years (66\%). According to Indonesia Basic Health Research 2013, asthma was more prevalent in females than in males (4.6\% versus $4.4 \%$ ). In addition, those aged $<55$ years (14.7) have a higher prevalence of asthma than those aged $\geq 55$ years $(8.3 \%)$.

We found that 12 subjects had normal spirometry result $\left(\mathrm{FEV}_{1} \%>80 \%\right.$ and $\left.\mathrm{FEV}_{1} / \mathrm{FVC} \geq 80 \%\right)$. Since at the first observation, they had completely controlled asthma. They reported a history of asthma and most of the subjects used inhalers when their asthma was exacerbated. There were 27 pilgrims (40\%) experienced asthma exacerbations during Hajj pilgrimage. The subjects had a median BMI of $20.24 \mathrm{~kg} /$ $\mathrm{m}^{2}$ and median $\mathrm{VO}_{2}$ max of $23.5 \mathrm{ml} / \mathrm{kgBW} / \mathrm{min}$. The $\mathrm{FEV}_{1}$ means (SD) were 1.54 (0.51) liters pre-bronchodilator and 1.59 (0.50) liters post-bronchodilator. Subjects with $\mathrm{FEV}_{1} \% \leq 80 \%$ had mean (SD) $\mathrm{FEV}_{1} \%$ values of $61.58 \%$ (17.37\%) pre-bronchodilator and $63.25 \%$ (16.86\%) postbronchodilator.

Based on bivariate analysis, obesity grade II caused significantly higher asthma exacerbation (prevalence ratio $[P R]=1.91,95 \%$ confidence interval $[\mathrm{Cl}]=1.10-3.29, p=0.033)$. Obesity and history of exacerbation one year before the Hajj were included

Table 1. Demographic and clinical characteristics of the subjects

\begin{tabular}{lc}
\hline Characteristics & $\mathrm{n}(\%)(\mathrm{N}=68)$ \\
\hline Female sex & $46(68)$ \\
\hline Age (years) & \\
$<60$ & $45(66)$ \\
$\geq 60$ & $23(34)$ \\
\hline Education & \\
\hline No school & $2(3)$ \\
\hline Elementary school & $5(7)$ \\
\hline Junior high school & $5(7)$ \\
\hline Senior high school/equivalent & $26(38)$ \\
\hline Bachelor/equivalent & $25(37)$ \\
\hline Master & $5(7)$ \\
\hline
\end{tabular}

Table 1. (continued)

\begin{tabular}{lc}
\hline Characteristics & $\mathrm{n}(\%)(\mathrm{N}=68)$ \\
\hline Occupation & \\
\hline Housewife & $28(41)$ \\
\hline Private employee & $8(12)$ \\
\hline Government employee & $9(13)$ \\
\hline Pensionary & $12(18)$ \\
\hline Others* & $11(16)$ \\
\hline Smoking & $19(28)$ \\
\hline Comorbidities (N = 39) & $6(9)$ \\
\hline Diabetes mellitus & $27(40)$ \\
\hline Hypertension & $6(9)$ \\
\hline Coronary heart disease & $48(71)$ \\
\hline History of exacerbation one year before Hajj & \\
\hline BMI & $32(47)$ \\
\hline No obesity & $20(29)$ \\
\hline Obesity grade I & $16(24)$ \\
\hline Obesity grade II
\end{tabular}

Fitness level $(N=60)$

$\begin{array}{lc}\text { Less } & 25(42) \\ \text { Fairly } & 35(51) \\ \text { Influenza vaccination } & 60(88) \\ \text { History of trigger of exacerbation/allergy } & \\ \text { Dust } & 45(66) \\ \text { Food } & 11(16) \\ \text { Drugs }^{\dagger} & 13(19) \\ \text { Weather }^{+} & 26(38) \\ \text { Fatigue } & 8(12) \\ \text { Psychological }^{\ddagger} & 4(6) \\ \text { Others }^{\ddagger} & 17(25)\end{array}$

Spirometry results

\begin{tabular}{lc}
$\mathrm{FEV}_{1} \% \leq 80 \%$ pre-bronchodilator & $56(82)$ \\
$\mathrm{FEV}_{1} / \mathrm{FVC}<80 \%$ pre-bronchodilator & $56(82)$ \\
$\mathrm{FEV}_{1} \% \leq 80 \%$ post-bronchodilator & $56(82)$ \\
$\mathrm{FEV}_{1} / \mathrm{FVC}<80 \%$ post-bronchodilator & $56(82)$ \\
Asthma severity & \\
\hline Intermittent & $7(10)$ \\
\hline Mildly persistent & $17(25)$ \\
\hline Moderately persistent & $33(49)$ \\
Severely persistent & $11(16)$ \\
\hline
\end{tabular}

$\mathrm{BMI}=$ body mass index; $\mathrm{FEV}_{1} \%=$ percentage of forced expiratory volume in 1 second; $F V C=$ forced vital capacity

*Entrepreneurs, teachers, and midwife; tantibiotics and painkillers; †cats, pollution (e.g. car/motorcycle fumes); §based on data collected at the puskesmas (2012 National Institute of Health criteria) 
in multivariate analysis (Table 2). ACT scores assessed before and during the Hajj is showed in Table 3 and 4.

\section{DISCUSSION}

A history of exacerbation one year before the Hajj and obesity grade II significantly increased the risk of asthma exacerbation during the pilgrimage. The history of exacerbation had an OR of 4.27, which is higher than obesity grade II $(O R=4.02 ; p<0.05)$. Unfortunately, there were wide range of the $\mathrm{Cls}$ due to small sample size. Other variables, including comorbidities, lung function, fitness level, smoking, obesity grade I, and influenza vaccination had no significant risk to exacerbation. Among 39 cases with severe asthma, $10.2 \%$ experienced exacerbations at least three times in the previous year. ${ }^{16}$ Puranik et $a^{17}$ reported that uncontrolled asthma is linked to future exacerbations. A cross-sectional study in Brazil found three factors that could be associated with uncontrolled asthma: severity of asthma, access to medication, and use of inhaled corticosteroids. ${ }^{18}$ Asthma patients with obesity experienced more exacerbations than asthma patients with low or normal BMI ( $n=1,127 ; 53 \%$ versus $47 \%) .{ }^{19}$ In addition, patients with asthma and obesity have been demonstrated to be at greater risk for hospitalization than other patients without these conditions. Stanford et $\mathrm{al}^{20}$ identified $\mathrm{BMI}>30 \mathrm{~kg} / \mathrm{m}^{2}$ as one of the most common predictors of uncontrolled asthma in adults. The mechanisms of asthma exacerbation related to obesity include reduced expiratory reserve and tidal volumes, airway hyperreactivity, and increased inflammatory markers in the form of interleukin 6 and C-reactive protein. ${ }^{21,22}$

Influenza vaccination has been proven to reduce risk and severity of influenza. Therefore, we believed that influenza vaccination could reduce the incidence of asthma exacerbation, although this study did not find reduction of asthma exacerbation. There were $88 \%$ subjects had influenza vaccination in this study and it was similar to the study of Iranian pilgrims who had vaccination (88.3\%).. ${ }^{23}$ Our results identify the need for further discussion on the concept of herd immunity and its relationship with influenza vaccination. The individuals who were not vaccinated may have experienced lower rates of exacerbation because of the effect of herd immunity. Rubio stated that herd immunity could be achieved if influenza vaccination is carried out in at least $80 \%$ of a certain population. ${ }^{24}$ While several studies have discussed the benefits of influenza vaccination and the role it plays in reducing asthma exacerbations, the results generally vary. ${ }^{25,26}$ To the best of our knowledge, there was no study on the role of influenza vaccination in reducing asthma exacerbation among Hajj pilgrims.

Table 2. Bivariate and multivariate analyses of factors associated with asthma exacerbation

\begin{tabular}{|c|c|c|c|c|c|c|}
\hline \multirow{3}{*}{ Variables } & \multicolumn{4}{|c|}{ Bivariate analysis* } & \multicolumn{2}{|c|}{ Multivariate analysis ${ }^{\dagger}$} \\
\hline & \multicolumn{2}{|c|}{ Asthma exacerbation } & \multirow{2}{*}{ PR $(95 \% \mathrm{Cl})$} & \multirow{2}{*}{$p$} & \multirow{2}{*}{ OR $(95 \% \mathrm{Cl})$} & \multirow{2}{*}{$p$} \\
\hline & Yes, n (\%) (N = 68) & No, $n(\%)(N=68)$ & & & & \\
\hline $\begin{array}{l}\text { History of exacerbation } \\
\text { one year before the Hajj }\end{array}$ & $23(48)$ & $25(52)$ & $2.39(0.95-6.04)$ & 0.061 & $4.27(1.156-15.829)$ & 0.029 \\
\hline Comorbidities & $14(45)$ & $17(55)$ & $1.28(0.71-2.30)$ & 0.400 & & \\
\hline Lung function & & & & 0.520 & & \\
\hline $\mathrm{FEV}_{1} \% \leq 80 \%$ & $21(37)$ & $35(63)$ & $0.75(0.38-1.44)$ & & & \\
\hline Fitness level $\left(\mathrm{VO}_{2} \max \right)$ & & & & 0.825 & & \\
\hline Less & $10(40)$ & $15(60)$ & $0.93(0.50-1.72)$ & & & \\
\hline Fairly & $15(43)$ & $20(57)$ & & & & \\
\hline Obesity grade I & $7(35)$ & $13(65)$ & $1.32(0.45-3.91)$ & 0.609 & & \\
\hline Obesity grade II & $10(63)$ & $6(37)$ & $1.91(1.10-3.29)$ & 0.033 & $4.02(1.151-14.097)$ & 0.029 \\
\hline Smoking & $8(42)$ & $11(58)$ & $1.08(0.57-2.04)$ & 0.801 & & \\
\hline Influenza vaccination & $24(40)$ & $36(60)$ & $0.93(0.36-2.41)$ & 0.893 & & \\
\hline
\end{tabular}

$\mathrm{PR}=$ prevalence ratio; $\mathrm{Cl}=$ confidence interval; $\mathrm{OR}=\mathrm{odds}$ ratio; $\mathrm{FEV}_{1} \%=$ percentage of forced expiratory volume in 1 second; $\mathrm{VO}_{2}$ max=maximal oxygen consumption

*Chi-square test; ${ }^{\dagger}$ logistic regression 
Table 3. Number of subjects based on lung function and ACT score before Hajj

\begin{tabular}{lccc}
\hline \multirow{2}{*}{ Lung function } & \multicolumn{3}{c}{ ACT score, $\mathrm{n}(\%)$} \\
\cline { 2 - 4 } & $\begin{array}{c}\text { Not controlled } \\
(\mathrm{N}=22)\end{array}$ & $\begin{array}{c}\text { Partially controlled } \\
(\mathrm{N}=27)\end{array}$ & $\begin{array}{c}\text { Fully controlled } \\
(\mathrm{N}=19)\end{array}$ \\
\hline $\mathrm{FEV}_{1} \% \leq 80 \%$ & $17(30)$ & $25(45)$ & $14(25)$ \\
$\mathrm{FEV}_{1} \%>80 \%$ & $5(42)$ & $2(16)$ & $5(42)$ \\
\hline
\end{tabular}

$\mathrm{ACT}=$ asthma control test; $\mathrm{FEV}_{1}$ \%=percentage of forced vital capacity

\begin{tabular}{lccc}
\hline \multirow{3}{*}{ Lung function } & \multicolumn{3}{c}{ ACT score, $\mathrm{n}(\%)$} \\
\cline { 2 - 4 } & $\begin{array}{c}\text { Not controlled } \\
(\mathrm{N}=11)\end{array}$ & $\begin{array}{c}\text { Partially controlled } \\
(\mathrm{N}=26)\end{array}$ & $\begin{array}{c}\text { Fully controlled } \\
(\mathrm{N}=31)\end{array}$ \\
\hline $\mathrm{FEV}_{1} \% \leq 80 \%$ & $6(11)$ & $24(43)$ & $26(46)$ \\
$\mathrm{FEV}_{1} \%>80 \%$ & $5(42)$ & $2(16)$ & $5(42)$ \\
\hline
\end{tabular}

$\mathrm{ACT}=$ asthma control test; $\mathrm{FEV}_{1} \%$ =percentage of forced vital capacity
Table 4. Number of subjects based on lung function and ACT score during the Haji and side effects of steroids were the major factors for reduction of compliance in asthma patiens. ${ }^{33}$ Nearly half of all asthma patients in the emergency setting were not formally educated about asthma and used their asthma devices improperly. ${ }^{34}$

Although asthma is well known to be associated with progressive declines in lung function, this correlation has yet to be fully explained. Some patients with asthma show a reversibility in acute attack and are turned into a normal lung function. Others, however, may experience irreversible obstructions that persist despite bronchodilator or corticosteroid treatment. In a study assessing Denmark's population, $\mathrm{FEV}_{1}$ values were measured in 17,506 subjects, including 1,095 asthmatic individuals, over a period of 15 years. The results revealed that, while the FEV values of subjects with asthma decreased by $38 \mathrm{ml} /$ year, the $\mathrm{FEV}_{1}$ values of normal individuals decreased by $22 \mathrm{ml} /$ year. ${ }^{35} \mathrm{In}$ another study that evaluated 228 adults with asthma who were followed for 21-33 years at a clinic in Groningen, the Netherlands, $16 \%$ of the subjects had irreversible airway obstructions that were characterized by an $\mathrm{FEV}_{1} \%<80 \%$ and a predictive reversibility of $<9 \% .^{36}$

The study examining the relationship between $\mathrm{VO}_{2}$ max and asthma exacerbations, especially among in Hajj pilgrims, is unavailable. However, several studies comparing $\mathrm{VO}_{2}$ max in asthmatic patients before and after intervention with an exercise program have been published. For instance, in Toennesen's assessment of 29 adult subjects with asthma, the patients' $\mathrm{VO}_{2}$ max increased after an 8-week intervention of exercise from a mean (SD) of $38.4(8.9) \mathrm{ml} / \mathrm{min} / \mathrm{kg}$ to a mean of $41.5(9.5) \mathrm{ml} / \mathrm{min} / \mathrm{kg}(p<0.001) .^{37}$ 
A previous study has concluded that smoking plays a significant role in asthma exacerbation because asthmatic patients who smoke have asthma characteristics different from those of non-smokers, including increased morbidity and mortality, more severe symptoms, more difficulty in controlling asthma, greater frequency of asthma exacerbations, and reduced quality of life. ${ }^{38}$ Bittner et al ${ }^{39}$ found that onethird of all asthmatic patients who visited emergency units in the United States are active smokers. However, in our study, we found no significant effect of smoking to asthma exacerbation.

Pilgrims with asthma can establish various behavioral adjustments to minimize their risk of disease exacerbation. Obese pilgrims are advised to lose weight. In a randomized controlled trial study on asthmatic patients, a low-calorie diet and routine exercise for 12 weeks improved the quality of life and achieved $5-10 \%$ weight loss in $80 \%$ of the subjects. ${ }^{40}$ Weight loss can exert positive effects on a patient's ability to control their asthma. Pilgrims who experience exacerbations one year before their pilgrimage are also recommended to monitor their asthma strictly. Taking medication regularly, avoiding exacerbation triggers, and regular exercise (e.g., aerobic and nonaerobic exercises) are several methods that can help prevent exacerbations. Minimizing exacerbations could also help to reduce a lung function deterioration. 35,36 Asthmatics who are active smokers are advised to quit. Although this study identified no significant effect of smoking to an exacerbation, other studies found that smoking increased asthma exacerbations. 38,39 Pilgrims with asthma, diabetes, hypertension, and CHD are advised to achieve better control of their diseases before embarking on their Hajj. Although no significant effect of comorbidities to asthma exacerbation was determined in this study, individuals with asthma in addition to diabetes, hypertension, or CHD are at greater risk of increased morbidity compared with those without these comorbidities. ${ }^{27,28,30,31}$

This study is the first to assess the relationship between risk factors and asthma exacerbation among Hajj pilgrims. At the Indonesian Hajj Health office (Kantor Kesehatan Haji Indonesia) in Makkah, Saudi Arabia, one of this study's authors acted as an on duty physician who visited subjects at their hotels. This service helped reduce bias during the monitoring of asthma exacerbations. We also collaborated with TKHI physicians to monitor subjects during their Hajj so that exacerbations could be monitored regularly. At the time of embarkation, subjects were given education and forms that they were asked to fill out in Saudi Arabia. Moreover, we participated in the data retrieval process so that errors in data retrieval could be minimized.

This study was limited by its evaluation of secondary data. For instance, the assessment of the subjects' fitness level by medical staff at the puskesmas could have been improved if we had directly monitored the subjects during their Rockport or six-minute walk tests. In addition, many other pilgrims with asthma from DKI Jakarta may not have been evaluated in this study. For example, at least 11 pilgrims with asthma missed their medical examinations before their Hajj and remained unlisted in the Integrated Hajj Computerization System. Among these pilgrims, nine pilgrims eventually became study subjects and completed a spirometry test upon their arrival in Indonesia. This could become bias to this study result. The small sample size in this work may also have contributed to the wide range of Cls obtained.

In conclusion, among the seven factors potentially influencing asthma exacerbation examined in this study, obesity grade II and a history of asthma exacerbation one year before the Hajj pilgrimage revealed significant risk factor for an asthma exacerbation. Pilgrims with asthma are advised to make behavioral adjustments to avoid these risk factors. For example, obese pilgrims may attempt to lose weight. Pilgrims are also advised to monitor their asthma symptoms strictly if they had experienced exacerbations at least one year before their Hajj.

\section{Conflict of Interest}

The authors affirm no conflict of interest in this study.

\section{Acknowledgment}

We thank the Head of Hajj Health Center (Kepala Pusat Kesehatan Haji Kementerian Kesehatan Republik Indonesia), Dr. dr. Eka Jusup Singka, MSc and all the committee who gave authors permissions to be part of the Hajj Organizing Committee (Panitia Penyelenggara Ibadah Haji) 2018. Author also thank all Indonesian Hajj Health Office (Kantor Kesehatan Haji Indonesia) 2018 team for their support and collaboration during Hajj 2018 and the $3^{\text {rd }}$ ICE on IMERI Committee for supporting our peer review and guiding our manuscript preparation process.

Funding Sources

This study was funded by Universitas Indonesia (PITTA Grant).

\section{REFERENCES}

1. General Authority for Statistics, Kingdom of Saudi Arabia. Hajj statistics for the year $1438 \mathrm{H}$ [Internet]. 2017 [cited 2018 Jan 26]. 
Available from: https://www.stats.gov.sa/en/5633.

2. Direktorat Jenderal Penyelenggaraan Haji dan Umrah Kementerian Agama Republik Indonesia. Dasar hukum haji dan umroh. [cited 2018 Oct 22]. Available from: http://haji.kemenag. go.id. Indonesian.

3. Gastrad AR, Sheikh A. Hajj: journey of a lifetime. BMJ. 2005;330(7483):133-7.

4. Indonesian Haij Health Center, Ministry of Health of the Republic of Indonesia. 2016 Hajj health center performance report. Jakarta: Ministry of Health of the Republic of Indonesia; 2016. Indonesian.

5. Indonesian Hajj Health Center, Ministry of Health of the Republic of Indonesia. 2017 Hajj health center performance report. Jakarta: Ministry of Health of the Republic of Indonesia; 2017. Indonesian.

6. Al-Ghamdi SM, Akbar HO, Qari YA, Fathaldin OA, Al-Rashed RS. Pattern of admission to hospitals during Muslim pilgrimage (Haji). Saudi Med J. 2003;24(10):1073-6.

7. Baharoon S, Al-Jahdali H, Al Hashmi A, Memish ZA, Ahmed QA. Severe sepsis and septic shock at the Hajj: etiologies and outcomes. Travel Med Infect Dis. 2008;7(4):247-52.

8. Global Initiave for Asthma. Pocket guide asthma management and prevention (for adults and children older than 5 years): a pocket guide for health professional updated 2017. Fontana: Global Initiave for Asthma; 2017.

9. Schatz M, Mosen DM, Kosinski M, Vollmer VM, Magid DJ, O'Connor E, et al. Validity of the Asthma Control Test completed at home. Am J Manag Care. 2007;13(12):661-7.

10. American Thoracic Society (ATS). Asthma Control Test (ACT) [Internet]. 2017 [cited 2018 Jan 26]. New York: American Thoracic Society (ATS). Available from: https://www.thoracic. org/members/assemblies/assemblies/srn/questionaires/act. php.

11. Schanen JG, Iribarren C, Shahar E, Punjabi NM, Rich SS, Sorlie PD, et al. Asthma and incident cardiovascular disease: the atherosclerosis risk in communities study. Thorax. 2005;60(8):633-8.

12. Herdy AH, Caixeta A. Brazilian cardiorespiratory fitness classification based on maximum oxygen consumption. Arq Bras Cardiol. 2016;106(5):389-95.

13. Pollack ML, Schmidt DH, Jackson AS. Measurement of cardiorespiratory fitness and body composition in the clinical setting. Compr Ther. 1980;6(9):12-27.

14. Graham BL, Steenbruggen I, Miller MR, Barjaktarevic IZ, Cooper BG, Hall GL, et al. Standardization of spirometry 2019 update. An Official American Thoracic Society and European Respiratory Society technical statement. Am J Respir Crit Care Med. 2019;200(8): e70-88.

15. National Heart, Lung, and Blood Institute. Guidelines for the diagnosis and management of asthma (EPR-3). USA: U.S. Department of Health and Human Services, National Institutes of Health, National Heart, Lung, and Blood Institute; 2012.

16. ten Brinke A, Sterk PJ, Masclee AA, Spinhoven P, Schmidt JT, Zwinderman $\mathrm{AH}$, et al. Risk factors of frequent exacerbations in difficult-to-treat asthma. Eur Respir J. 2005;26(5):812-8.

17. Puranik S, Fomo E, Bush A, Celedón JC. Predicting severe asthma exacerbations in children. Am J Respir Crit Care Med. 2017;195(7):854-9.

18. Dalcin PT, Menegotto DM, Zanonato A, Franciscatto L, Soliman $\mathrm{F}$, Figueiredo $\mathrm{M}$, et al. Factors associated with uncontrolled asthma in Porto Alegre, Brazil. Braz J Med Biol Res. 2009;42(11):1097-103.

19. Hasegawa K, Tsugawa Y, Lopez BL, Smithline HA, Sullivan AF, Camargo CA Jr. Body mass index and risk of hospitalization among adults presenting with asthma exacerbation to the emergency department. Ann Am Thorac Soc. 2014;11(9):143944.

20. Stanford RH, Gilsenan AW, Ziemiecki R, Zhou X, Lincourt WR, Ortega $\mathrm{H}$. Predictors of uncontrolled asthma in adult and pediatric patients: analysis of the Asthma Control Characteristics and Prevalence Survey Studies (ACCESS). J Asthma. 2010;47(3):257-62.

21. Umetsu DT. Mechanisms by which obesity impacts upon asthma. Thorax. 2017;72(2):174-7.

22. Gibson PG. Obesity and asthma. Ann Am Thorac Soc. 2013;10Suppl:S138-42.

23. Meysamie A, Ardakani H, Razavi SM, Doroodi T. Comparison of mortality and morbidity rates among Iranian pilgrims in Haji 2004 and 2005. Saudi Med J. 2006;27(7):1049-53.

24. Plans-Rubió P. The vaccination coverage required to establish herd immunity against influenza viruses. Prev Med. 2012;55(1):72-7.

25. Vasileiou R, Sheikh A, Butler C, El Ferkh K, von Wissmann B, McMenamin J, et al. Effectiveness of influenza vaccines in asthma: a systematic review and meta-analysis. Clin Infect Dis. 2017;65(8):1388-95.

26. Cates $\mathrm{CJ}$, Rowe $\mathrm{BH}$. Vaccines for preventing influenza in people with asthma. Cochrane Database Syst Rev. 2013;2013(2):CD000364.

27. Wang L, Gao S, Yu M, Sheng Z, Tan W. Association of asthma with coronary heart disease: a meta analysis of 11 trials. PLoS One. 2017;12(6):e0179335.

28. Thuesen BH, Husemoen LL, Hersoug LG, Pisinger C, Linneberg A. Insulin resistance as a predictor of incident asthma-like symptoms in adults. Clin Exp Allergy. 2009;39(5):700-7.

29. Rana JS, Mittleman AM, Sheikh J, Hu FB, Manson JE, Colditz GA, et al. Chronic obstructive pulmonary disease, asthma, and risk of type 2 diabetes in women. Diabetes Care. 2004;27(10):2478-84.

30. Christiansen SC, Schatz M, Yang SJ, Ngor E, Chen W, Zuraw BL. Hypertension and asthma: a comorbid relationship. J Allergy Clin Immunol Pract. 2016;4(1):76-81.

31. Dart RA, Gollub S, Lazar J, Nair C, Schroeder D, Woolf SH. Treatment of systemic hypertension in patients with pulmonary disease: COPD and asthma. Chest. 2003;123(1):222-43.

32. Schatz M, Zeiger RS, Drane A, Harden K, Cibildak A, Oosterman $\mathrm{JE}$, et al. Reliability and predictive validity of the Asthma Control Test administered by telephone calls using speech recognition technology. J Allergy Clin Immunol. 2007;119(2):336-43.

33. Al-Jahdali HH, Al-Zahrani Al, Al-Otaibi ST, Hassan IS, Al-Moamary MS, Al-Duhaim AS, et al. Perception of the role of inhaled corticosteroids and factors affecting compliance among asthmatic adult patients. Saudi Med J. 2007;28(4):569-73.

34. Al-Jahdali H, Anwar A, Al-Harbi A, Baharoon S, Halwani R, Al Shimemeri $A$, et al. Factors associated with patient visits to the emergency department for asthma therapy. BMC Pulm Med. 2012;12:80.

35. Ortega H, Yancey SW, Keene ON, Gunsoy NB, Albers FC, Howarth $\mathrm{PH}$. Asthma exacerbation associated with lung function decline in patients with severe eosinophilic asthma. J Allergy Clin Immunol Pract. 2018;6(3):980-6.e1.

36. O'Byrne PM, Pedersen S, Lamm CJ, Tan WC, Busse WW; START Investigators Group. Severe exacerbations and decline in lung function in asthma. Am J Respir Crit Care Med. 2009;179(1):19-24.

37. Toennesen LL, Soerensen ED, Hostrup M, Porsbjerg C, BangsboJ, Backer V. Feasibility of high-intensity training in asthma. Eur Clin Respir J. 2018;5(1):1468714.

38. Bumbacea D, Campbell D, Nguyen L, Carr D, Barnes PJ, Robinson $\mathrm{D}$, et al. Parameters associated with persistent airflow obstruction in chronic severe asthma. Eur Respir J. 2004;24(1):122-8.

39. Bittner JC, Hasegawa K, Silverman RA, Camargo CA Jr. Smoking cessation intervention among adults hospitalized with asthma exacerbation [abstract]. Ann Emerg Med. 2015;66(4 Suppl 136). Abstract no. 374.

40. Scott HA, Gibson PG, Garg ML, Pretto JJ, Morgan PJ, Callister $\mathrm{R}$, et al. Dietary restriction and exercise improve airway inflammation and clinical outcomes in overweight and obese asthma: a randomized trial. Clin Exp Allergy. 2013;43(1):36-49. 